\title{
Antropomorfismo e ontologia da violência em Schopenhauer
}

\author{
ÁDAMO BOUÇAS ESCOSSIA DA VEIGA *
}

* PPGF-FIL

PUC- RIO

Doutorando

Bolsista CAPES

\begin{abstract}
RESUMO O presente trabalho pretende analisar a filosofia de Arthur Schopenhauer a partir da noção filosófica contemporânea de "antropomorfismo". Trata-se de um método de especulação filosófica que procura o em si do mundo no em si do sujeito. Analisando o sistema filosófico do autor através deste método, observamos a presença de uma violência metafísica no movimento de objetificação da Vontade, descrito pelo filósofo como modo de gênese do mundo fenomênico. Procuramos demonstrar este ponto a partir de uma reflexão acerca deste movimento genético na concepção schopenhauriana das Ideias, fortalecendo-o, em seguida, a partir de uma análise dos conceitos de justiça e injustiça. A título de conclusão, exporemos a ética defendida pelo autor em resposta a sua concepção agonística e pessimista do mundo.
\end{abstract}

PALAVRAS-CHAVE Schopenhauer, violência, antropomorfismo, justiça.

\section{INTRODUÇÃo}

O presente trabalho pretende demonstrar uma possível ontologia da violência no sistema metafísico de Arthur Schopenhauer. Tal sistema, se se orienta por um pessimismo que o torna possivelmente pouco atrativo hoje, no entanto, se revela, a nosso ver, muito relevante em diversos aspectos, sobretudo, pelo seu desenvolvimento ético. Em um mundo tal como o que vivemos, no qual o neoliberalismo faz do egoísmo uma virtude, no qual a ética se diz do prazer, da vitória e do ganho, a filosofia de Schopenhauer pode figurar como um verdadeiro bálsamo ${ }^{1}$. De forma ainda mais contundente, a narrativa prometaica do homem como conquistador da natureza, ao

1 Sobre a relação entre a ética de Schopenhauer e o egoísmo contemporâneo, típico das sociedades de consumo, Cf. Bittencourt, 2016 
retirar a subjetividade do mundo, reduzindo-a a pura matéria a-subjetiva, sem agência ou vontade, traz junto de si a ameaça da erradicação da própria espécie humana na medida em que as condições materiais da vida se esgotam. Temos aqui, nesta cisão entre homem e mundo - típica da narrativa moderna do "progresso" - uma das figuras daquilo que Whitehead (1994) chama de "bifurcação da natureza": a cisão do mundo entre a sua apresentação a nós e o seu ser em si mesmo. Se Whitehead situa este movimento mais propriamente em Descartes, devemos concordar com Steven Shaviro (2009) quando este nos diz que, de fato, é a disjunção entre sujeito e coisa em si na crítica de Kant (na primeira crítica, sobretudo) que sustenta, ao longo da modernidade, a natureza bifurcada em sua mais vívida expressão.

Neste sentido, o sistema metafísico de Schopenhauer nos parece exemplar. Respondendo diretamente à problemática kantiana, a sua solução se aproxima em muito do que hoje se chama antropomorfismo, no sentido que lhe dá Danowski e Viveiros de Castro(2015) e Pierre Montebello (2015), porém, cujas raízes, como demonstraremos, podem ser encontradas em diversos outros autores. Trata-se de buscar no em si da experiência o caminho para a postulação de enunciados ontológicos acerca do mundo sem nós. O mundo em si, para além do fenômeno, torna-se pensável na medida em que nós mesmos somos uma coisa em si. Não se trata de projetar a imagem do homem no mundo, mas de deslocar o humano da sua centralidade a partir da continuidade que vai dele ao mundo. Neste sentido, podemos ver como, em Schopenhauer, a natureza (entendida aqui como exterioridade a nós) não se diz em uma disjunção radical ao humano, mas antes é por este acessível na medida em que este simplesmente é, sem que isso configure, no entanto, um retorno à ingenuidade metafísica pré-crítica - o que se sustenta na central divisão entre o mundo como Vontade e o mundo como representação. A unidade metafísica destes dois mundos- que, inclusive, fundamenta a sua ética - escapa à bifurcação da natureza na medida em que se trata de uma unidade imanente e não mais de uma disjunção transcendente.

Pretenderemos trabalhar tal antropomorfismo a partir da possibilidade de uma ontologia da violência na filosofia de Schopenahauer. A unidade homem e mundo muitas vezes é trabalhada sob a forma pouco filosófica de um Éden ou mãe prodigiosa, algo inteiramente ausente, ao que nos parece, da conceptualização do filósofo. Pelo contrário, a natureza, em seu sistema, figura como puro agon, uma violência ontológica primordial. O ponto relevante aqui é, sobretudo, o fato de a ética elaborada a partir 
desta questão não se dar através de uma pureza original do homem ou uma identificação da natureza com a moral ${ }^{2}$, mas, pelo contrário, se dar em um verdadeiro movimento de contra-natureza no qual deve-se superar o egoísmo natural e a violência metafísica da Vontade em sua manifestação fenomênica. Para Schopenhauer, não se trata de procurar no homem a moral e a virtude enquanto propriedades adormecidas a serem despertadas, mas, antes, a partir da constatação de um inexorável egoísmo no seio do homem, pensar uma possibilidade ética orientada ao problema metafísico da unidade substancial do mundo. Para tal, procuraremos expor o caráter agônico da Vontade, para em seguida, compará-lo com as elucidações do autor no que tange à injustiça. Em seguida, a título de conclusão, exporemos a sua saída ética ao dilema posto pela sua própria metafísica da violência.

\section{ANTROPOMORFISMO E METAFÍSICA DA VONTADE}

A filosofia de Schopenhauer não comporta em si mesmo o termo antropomorfismo. No entanto, já ensaia uma forma de pampsiquismo como bem demonstra Skrbina (2005) e este, se não pode ser dito um antropomorfismo per se, flerta com ele de forma muito próxima ao postular um princípio antropomórfico tal como a mente em todos os seres. A definição apresentada por Danowski e Viveiros de Castro, por exemplo, baseia-se na metafísica dos ameríndios brasileiros, enxergando nela o princípio antropomórfico em sua efetiva operação de deslocamento do antropocentrismo. Segundo os autores, para o os índios, naquilo que foi conceptualizado enquanto "perspectivismo ameríndio", a humanidade não está apartada da natureza. Para eles, o termo "homem" ou "humano" possui uma função meramente operatória: todo ente, espécie animal ou vegetal, se enxerga tal como o humano de modo que "eles não são humanos para nós, mas nós sabemos que eles são humanos para si."3 O que nos interessa aqui é o fato de que a humanidade perde sua excepcionalidade na precisa medida em que ela se estende a todos os seres. A bifurcação da natureza não faz sentido neste contexto em que a humanidade se diz de todos os seres. Assim,

2 Neste ponto, Deleuze denuncia, sem, no entanto, mencionar a obra de Schopenhauer, os problemas que uma assunção pré-filosófica de uma boa natureza do pensamento - a sua tendência a verdade e ao bom - colocam à filosofia crítica kantiana. (Deleuze, 2000, p. 134-136)

3 Danowski, Viveiros de Castro, 2015, p.96 
Definiremos então as ontologias "animistas" dos Ameríndios e povos congêneres como manifestando o princípio antropomórfico de modo a contrastá-las com o princípio antropocêntrico que nos parece constituir um dos pilares mais firmemente fixados na metafísica ocidental [...] Neste sentido o antropomorfismo é uma inversão irônica completa (dialética?) do antropocentrismo. Dizer que tudo é humano é dizer que os humanos não são uma espécie especial, um evento excepcional que veio interromper magnífica ou tragicamente a trajetória monótona da matéria no universo. ${ }^{4}$

Mas, em que sentido, poderíamos comparar sistemas de pensamentos tão distante e diversos quanto os ameríndios e Schopenhauer? Acreditamos que tal comparação se torna possível não a nível histórico, naturalmente, mas a nível propriamente filosófico. É necessário frisar, no entanto, que o antropomorfismo inspira-se na cosmologia ameríndia, não consistindo em uma simples descrição do modo de pensar indígena, mas, antes, uma apropriação de temas antropológicos para uma reflexão alinhada à problemas típicos da metafísica ocidental tradicional, tal como a centralidade do humano em detrimento da natureza. Trata-se de um movimento de pensar com os índios e não apenas de descrevê-los ou analisá-los.

A interpretação da cosmologia ameríndia presente acima tem, assim, em comum com a filosofia de Schopenhauer o descentramento do antropocentrismo pela via do antropomorfismo. Em Schopenhauer, todos os entes em si mesmos compartilham o mesmo substrato comum enquanto Vontade, sendo esta definida a partir de uma análise introspectiva do humano na busca pelo seu ser em si mesmo. Agora, tendo apresentado uma definição do que seria o princípio antropomórfico, faremos uma breve exposição dos elementos centrais da metafísica de Schopenhauer.

Em Schopenhauer, como exposto em “O Mundo como Vontade e Representação” (2015), temos, a partir de um arcabouço kantiano, a afirmação da possibilidade do conhecimento da coisa em si pelo simples fato de sermos em nós mesmos uma coisa em si. Bem próximo a Kant, Schopenhauer postula um mundo para nós, o mundo da representação, sujeito às categorias do entendimento, ou melhor, produzido inteiramente pela nossa cognição através da subordinação, operada por esta faculdade e pela intuição, ao princípio de razão - tempo, espaço e causalidade. Logo no início do 
primeiro livro da dita obra, Schopenhauer nos diz que "o mundo é minha representação" é o verdadeiro a priori, de modo que para aquele que conhece:

Torna-se claro e certo que não conhece Sol algum nem Terra alguma, mas apenas sempre um olho que vê um Sol, uma mão que toca uma Terra; que o mundo que o cerca só existe apenas como representação, isto é, tão somente em relação a outrem, aquele que representa, que é ele mesmo. 5

O mundo, neste sentido, é a construção subjetiva, uma operação do sujeito - "aquele que tudo conhece mas nunca é conhecido." ${ }^{6}$ Sujeito este que produz, através da intuição e do entendimento, a aparência do mundo.

Em par com este mundo, temos o mundo da vontade. O mundo como representação se dá na exterioridade das aparências em relação a um sujeito; o mundo como Vontade, por sua vez, revela-se através da introspecção. O corpo humano, corpo do sujeito, é um objeto como outro no mundo, porém, com a especificidade de não só ser conhecido externamente, de forma mediada pelo entendimento - como, por exemplo, o corpo dissecado pela anatomia ou a figura do rosto em uma fotografia - mas, igualmente, de ser percebido de forma imediata, - como eu percebo a minha mão no momento em que agarro um pedaço de terra, por exemplo. A compreensão da Vontade, então, se encontra para além de qualquer formalismo intelectual e cognitivo, sendo dada pela intuição imediata. O corpo, enquanto objeto imediato, assim, se vê possuidor de um duplo aspecto, sendo fenômeno, representação, e, igualmente, um algo a mais totalmente diferente da própria representação, algo em um outro mundo que não se subordina a este. Nas palavras do próprio Schopenhauer:

Ao sujeito do conhecimento, que por meio da sua identidade com o corpo entra em cena como indivíduo, este corpo é dado de duas maneiras completamente diferentes: uma vez como representação na intuição do entendimento, como objeto entre objetos e submetidos às leis destes; outra vez de maneira completamente outra, a saber, como aquilo conhecido imediatamente por cada um e indicado pela palavra VONTADE. ${ }^{7}$

5 Schopenhauer, 2015, p.3

6 Ibidem, p. 5

7 Schopenhauer, 2015, p. 116. 
A Vontade é o em si, distinto da representação. É o mundo sem nós, independente de nós, do qual somos apenas uma manifestação. Antes de mais nada, somos Vontade. O corpo possui a sua imediaticidade no fato de que a Vontade nele se efetua primeiramente, como quando, por exemplo, tenho vontade de mexer um braço e o mexo. Antes mesmo de perceber meu corpo empiricamente em seu movimento, de meus olhos ou meu tato me indicarem que algo se mexeu, eu percebo a vontade de mexê-lo, de forma tão imediata quanto o seu próprio movimento. Este fator, como coloca bem Roberto Barros, é o que permite a "Schopenhauer conferir uma significação metafísica do corpo e a percepção intuitiva nele manifesta, entendo-o como a presentificação espaço-temporal da Vontade e, por isso, a primeira via intuitiva de sua percepção.”8

Deste modo, Schopenhauer afirma que “o corpo inteiro não é nada senão vontade objetivada, que se tornou representação." 9 Objetivação aqui, significa individuação. A Vontade, sendo alheia ao princípio de razão, não possui em si indivíduos, aos quais, como veremos melhor, se individuam em sua pluralidade e singularidade apenas no mundo como representação.

Antes de prosseguirmos, gostaríamos de frisar, como bem coloca Renato Nogueira, que, em Schopenhauer, “a Vontade humana - o querer - foi ampliada vertiginosamente em sua extensão, constituindo a Vontade, no sentido metafísico, a face fundadora da realidade, isto é, tudo que existe e somos, independentemente das formas da representação." ${ }^{\circ}$ O que vemos neste trecho é precisamente o que chamamos de antropomorfismo: a derivação de um dado ao humano na sua constituição mesma (enquanto percepção de si) à totalidade metafísica da natureza.

Como dizemos a pouco, a Vontade é Una, dado que a pluralidade só pode existir sob o princípio de individuação, no espaço, tempo e causalidade. No mundo da representação, por sua vez, ela se manifesta na pluralidade, em diferentes indivíduos, sujeitos todos ao princípio de razão. A sua objetivação, o seu tornar-se objeto, indivíduo, possui um número infinito de manifestações possíveis, tão infinitas quando são as articulações possíveis de tempo, espaço e causalidade. A Vontade mesma, anterior a tal princípio tem, por consequência, que ser Una, alheia a toda pluralidade. Igual-

8 Barros, 2017, p.6

9 Schopenhauer, 2015, p. 116.

10 Nogueira, 2018, p.1 
mente, por estar verdadeiramente fora do princípio de razão, ela não pode possuir qualquer fundamento neste; ela é necessariamente sem fundamento, pois nada pode fundamentar aquilo que escapa às leis próprias do entendimento e da razão. Assim,

De tudo que foi dito se segue que a Vontade como coisa em si encontra-se fora do domínio do princípio de razão e de todas as suas figuras, e, por conseguinte, é absolutamente sem fundamento, embora cada uma de suas aparências esteja por inteiro submetida ao princípio de razão; ela é, pois, livre de toda PLURALIDADE, apesar de suas aparências no espaço e no tempo serem inumeráveis; ela é una: todavia, não no sentido de que um objeto é uno, cuja unidade é conhecida apenas em oposição a pluralidade possível, muito menos é una como um conceito, cuja unidade nasce apenas pela abstração da pluralidade: ao contrário, a vontade é una como aquilo que se encontra fora do tempo e do espaço, exterior ao principium individuationis, isto é, da possível pluralidade. ${ }^{11}$

A Vontade, então, é a experiência em si por excelência, o que nos assegura a apreensão daquilo que é exterior à representação; o mundo para além do que ele é para nós. Compartilhamos com o mundo o fato de sermos expressão da mesma e una Vontade, aparências de um mesmo substrato. As forças da natureza são sua expressão, como a gravitação entre os corpos celestes e o instinto sexual nos corpos animais e humanos. Somos diferentes formas de objetivação da Vontade, em uma pluralidade infinita, mas ainda, Vontade. Deste modo, a experiência íntima dada pela introspecção é aquilo que permite a filosofia ultrapassar às ciências da natureza na medida em que estas conhecem apenas a representação sujeita ao princípio de razão; para além da física, na metafísica, o em si enquanto Vontade, pode ser conhecido.

O antropomorfismo torna-se claro agora, uma vez que o modus operandi da metafísica de Schopenhauer é justamente a introspecção na experiência íntima do sujeito para, a partir do que aí é encontrado, realizar uma operação de homologia que estende o conhecimento do seu próprio em si mesmo aos demais entes. Neste sentido, a Vontade que se manifesta no homem, não lhe dá privilégio, pelo contrário, apenas atesta a sua imediata pertença ontológica aos demais seres. No seguinte trecho, o caráter não antropocêntrico da sua metafísica é bastante claro:

[...] a chave para a compreensão da essência em si das coisas, chave esta que só poderia ser dada pelo conhecimento imediato da nossa própria essência, tam-

11 Schopenhauer, 2015, p. 132 
bém tem de ser aplicada às aparências do mundo inorgânico, estas que são as mais distantes de nós. Assim, ao considerá-las sob o olhar investigativo, ao vemos o ímpeto poderoso a massa d'água se precipita nas profundidades, a persistência com a qual o imã sempre se volta ao polo norte, o anelo com que o ferro é atraído pelo ímã, a veemência com que os polos da eletricidade se esforçam por reunir-se, e, que, precisamente como os desejos humanos, é intensificada por obstáculos. [...], então, não custará grande esforço à imaginação reconhecer de novo a nossa própria essência até mesmo em tão grande distância. ${ }^{12}$

A unidade metafísica da Vontade não interdita a pluralidade no mundo da representação, mas antes, é da natureza da vontade a emergência desta. Os modos de objetidade da Vontade - que Schopenhauer denomina Ideias - constituem o nível mais fundamental desta emergência. As Ideias consistem na determinação formal, eterna e imutável, segundo a qual as infinitas possibilidades da aparência se veem condicionadas. Correspondem aos diversos graus de objetivação da Vontade, sendo estes as formas na qual os objetos singulares entretêm uma relação de cópia. Por exemplo, a Ideia do homem não estaria no homem singular, mas na humanidade como um todo, em todas as suas manifestações específicas ao longo da história.

Esta objetivação em graus, no entanto, faz com que Schopenhauer estabeleça uma hierarquia entre os entes: “as forças mais universais da natureza expõem-se como os graus mais baixos da objetivação da vontade"13 enquanto o ser humano, por sua vez, corresponde a um grau mais elevado de objetivação na medida em que é dotado de razão.

É necessário, no entanto, fazer uma breve ressalva aqui: para Schopenhauer, se a Vontade é a natureza numênica e condição da natureza fenomênica, e se podemos ver neste fato apenas, já um pampsiquismo ${ }^{14}$, isto não significa que a mente, intelecto ou razão, tal como nós humanos o possuímos esteja em todos os demais seres. Na verdade, é na pertença exclusiva da razão pelo humano que este pode ser dito o mais alto grau de objetivação da Vontade. Isso não quer dizer, no entanto, que este mais alto grau estabeleça uma hierarquia ontológica, mas antes, dado o caráter derivado da representação em relação à Vontade, atesta apenas uma diferença de grau e não de natureza. Neste sentido, como coloca Ruggieri “por mais que no topo, nos seres humanos,

12 Schopenhauer, 2015, p.138

13 Idem.

14 Seguimos a interpretação David Skrbina neste aspecto. (Skrbina, 2005, p. 117-122) 
haja a razão, esta não é absolutamente soberana na natureza, mas simplesmente (e sempre) escrava da Vontade." N5 Não há apoteose prometaica em Schopenhauer, mas apenas a subordinação da razão à unidade metafísica do mundo.

Neste sentido, ele critica Kant ${ }^{16}$ em sua necessária subsunção da ordem natural a uma inteligência superior ou intelecto. Pois, apenas a partir da superioridade e da disjunção radical entre homem e natureza que se obrigaria a razão à necessária suposição de um intelecto superior como condição da regularidade e ordem na natureza. Posição esta, que, ao ser refutada por Schopenhauer, atesta o caráter subordinado destes graus de objetivação, dados apenas no mundo da representação, à unidade ontológica fundamental da Vontade. Deste modo, Schopenhauer escreve que “o intelecto nos é conhecido apenas a partir da natureza animal e consequentemente como um princípio totalmente secundário e subordinado no mundo, um produto de origem tardia: ele não pode portanto jamais ser a condição de sua existência." ${ }^{17}$ Não é o intelecto (o entendimento, de forma mais precisa) o legislador do mundo, tal como em Kant, mas este nada mais é do que um efeito secundário do desenvolvimento imanente da natureza enquanto Vontade. Assim, como coloca Ruggieri, a ordem emergente a partir da dinâmica conflitante da Vontade na gênese fenomênica "não representa nenhum plano de uma entidade mais alta; não há plano teleológico de modo algum, dado que cada parte encontra sua razão de ser dentro de si mesma por conta do carácter fragmentado do mundo e da vida." 18

\section{VONTADE E VIOLÊNCIA}

É a partir destas considerações que Schopenhauer vê as mais terríveis consequências. A Vontade é primária em relação aos objetos de tal modo que estes não podem satisfazê-la. A satisfação de determinada vontade particular só enseja mais e mais. A Vontade não se deixa satisfazer pelos objetos; antes é um movimento dado a si mes-

15 Ruggieri, 2016, p. 143

16 Esta questão é desenvolvida por Kant na Crítica da Razão Pura (Kant [1781] 2001) e, principalmente, na Crítica da Faculdade de Julgar, na seção acerca da “Crítica do Julgamento Teleológico.” (Kant, [1790] 2016)

17 Schopenhauer, 2013, p. 89

18 Ruggieri, 2016, p. 145 
mo que nada mais faz do que se estender indefinidamente. ${ }^{19}$ Mais ainda, a vontade é contraditória em si mesma, conflituosa em si mesma ${ }^{20}$; e é desta contradição que o mundo como representação emerge de forma imanente ${ }^{21}$.

É neste ponto que a metafísica de Schopenhauer manifesta mais expressamente o caráter bélico do real. Pois, esta emergência - que podemos também chamar de individuação - é essencialmente violenta, procedendo por lutas, derrotas e conquistas. As Ideias entram em conflito entre si pela matéria (causalidade), tempo e espaço, e é a partir da "assimilação por dominação" ${ }^{22}$, onde as mais baixas se subordinam à determinação das mais elevadas, que a objetivação da Vontade evolui até graus mais elevados de perfeição. Por exemplo, no organismo vivo, vemos elementos do domínio inorgânico, como interações químicas e físicas, subordinados à forma mais elevada do corpo biológico. A Ideia mais elevada nada mais é do que uma Ideia conquistadora, forte, capaz de se impor às demais. Este movimento, certamente, não é colocado como algo glorioso em tom de exaltação ou ode. Antes é descrito como essencialmente trágico, não nos autorizando assim, nenhuma intepretação prometaica do homem enquanto suprema expressão de um processo de conquista da natureza.

Neste ponto, devemos dizer que, no entanto, as Ideias mais baixas, derrotadas, mesmo que "submetidas a servidão, sempre se esforçam por ser independentes e exteriorizar completamente a sua essência.”23 A morte, no caso dos seres vivos, decorre justamente desta resistência, “pois, finalmente, por circunstâncias favoráveis, as forças naturais subjugadas reconquistam a matéria que lhes foi arrebatada pelo organismo - agora cansado até mesmo pelas constantes vitórias [...]"24 Por mais que “não haja vitória sem luta” ${ }^{25}$, esta luta nunca cessa e a vitória nunca é definitiva, de tal modo que o conflito que enseja a subordinação de um grau de objetivação a outro se mantém atual na representação determinada. A Vontade não é um desígnio, como

19 Schopenhauer, 2015, p. 226

20 Quanto a esse ponto Cf. Barbera, 2004.

21 Schopenhauer, 2015,p.171

22 Ibidem, p. 169

23 Idem

24 Ibidem, p. 170

25 Ibidem, p. 164 
se fosse a realização da vontade de um deus, mas uma guerra permanente a nível metafísico entre as diversas aspirações das Ideias à manifestação. Há “contrariedade da vontade consigo mesma" 26 , conflito intrínseco neste movimento próprio de gênese. Nas palavras de Schopenhauer:

Assim, em toda parte da natureza vemos conflito, luta e alternância de vitória, e aí reconhecemos com distinção a discórdia essencial da Vontade consigo mesma. Cada grau de objetivação da vontade combate com outros por matéria, espaço e tempo. A matéria que subsiste tem continuamente que mudar de forma, na medida em que, pelo fio condutor da causalidade, aparência mecânicas, químicas, orgânicas, anseiam avidamente por emergir e assim arrebatam umas às outras a matéria, pois cada uma quer manifestar a sua própria Ideia.. ${ }^{27}$

Deste modo, pudemos ver que como o antropomorfismo de Schopenhauer leva a uma metafísica da violência e da guerra na medida mesma em que a Vontade, enquanto em si do mundo, é contraditória consigo mesma em seu movimento de gênese fenomênica, em um movimento que engendra o mundo da representação a partir da sucessão de conflitos e alianças entre as Ideias. A partir da experiência em si de si mesmo, Schopenhauer desce até a profundeza do em si no mundo encontrando nada além da unidade de uma vontade violenta em perpétua contradição com si mesma no seu movimento genético de constituição do mundo representacional.

\section{INJUSTIÇA E JUSTIÇA}

Nos parece, que tal violência se torna ainda mais clara quando Schopenhauer se debruça sobre a ética e política no quarto livro do primeiro tomo do Mundo. A primeira conclusão a ser tirada do ser enquanto Vontade, neste aspecto, é um egoísmo necessário da natureza humana, animal, e possivelmente de todos os entes: “eis aí a mentalidade do egoísmo o qual é essencial a cada coisa na natureza. É exatamente através dele que o conflito interno da Vontade consigo mesma alcança temível manifestação." ${ }^{28}$ Cada Ideia opera por uma fruição egoísta no seu processo de individuação imanente no mundo da representação. Como coloca Cartwright, Schopenhauer se "refere a centralidade do egoísmo no comportamento humano tanto

26 Ibidem, p. 171

27 Ibidem, p. 171

28 Ibidem p. 386 
através da sua metafísica da Vontade quanto da sua descrição fenomenológica da natureza." 29 Pela seção anterior, já podemos ver com o agon de objetivação da Vontade facilmente estrutura um egoísmo essencial da natureza humana, que como toda a natureza em geral, orienta-se para a máxima afirmação de si na luta por tempo, espaço e matéria. O sentido fenomenológico seria, por sua vez, a consciência, enquanto manifestação da Vontade, incapaz de enxergar o quanto a sua própria fruição egoística está em todos os outros seres de modo que estes também nada mais desejam do que seu próprio bem estar e fruição. Schopenhauer nos diz que, na natureza, o conflito entre animais, por exemplo, deixa clara a pulsão egoísta de cada ser vivo, que apenas procura maximizar a sua afirmação corporal e bem-estar em detrimento dos demais. O corpo é a instância primeira desta afirmação, pois é ele a primeira manifestação do mundo como representação. Assim, a contrariedade da Vontade em seu movimento imanente de gênese expressa-se no mundo da representação na forma de uma fruição egoística primeira, na qual cada corpo, cada ente individuado, luta com os demais do mesmo modo que as Ideias competem por matéria, tempo e espaço.

Neste sentido, Schopenhauer postula a injustiça como ontologicamente primeira - e não a justiça. O que o filósofo chama de injustiça é de todo próximo do que aqui definimos como violência, sendo esta última, no entanto, apenas utilizada pelo autor no sentido restrito de violência física. No seguinte trecho, temos a sua definição de injustiça|:

Na medida que, entretanto, a Vontade expõe aquela AUTOAFIRMAÇÃO do próprio corpo em inumeráveis indivíduos um ao lado do outro, tal autoafirmação em virtude do egoísmo inerente a todos, vai muito facilmente além de si mesma até a NEGAÇÃO da mesma vontade como essa aparece em outros indivíduos. [...] semelhante invasão dos limites da afirmação alheia da Vontade foi conhecida distintamente em todos os tempos, e seu conceito foi designado pelo nome de INJUSTIÇA."30

Deste modo, o canibalismo, exemplo um tanto pitoresco, figura como expressão mais viva desta injustiça na medida em que é o ato claro e direto de afirmação de uma vontade corporal, a nutrição, em detrimento da existência de outrem. O homicídio, a

29 Cartwright, 2006, p. 271

30 Schopenhauer, 2015, p. 388 
escravidão (a apropriação do trabalho do outro), são outros tantos exemplos da manifestação social e humana da violência intrínseca da Vontade enquanto injustiça. ${ }^{31}$

O sentido propriamente negativo da justiça deriva do fato dela mesmo ser derivada e não primeira em relação ao seu oposto; é uma não-injustiça: “O conceito de injustiça é originário e positivo: o posto a ele, o de justiça, é derivado e negativo.”32 É a afirmação de si mesmo que não viola a afirmação do outro em detrimento do impulso natural a fazê-lo. A justiça é um esforço contra a natureza em seu empuxo egoístico primitivo: “as ações justas são aquelas que não ultrapassam os limites traçados pela vontade do agente, limites estes que apaziguam seu egoísmo."33

Deste modo, pretendemos ter demonstrado como uma metafísica da Vontade institui uma ontologia da violência em Schopenhauer, sendo a primariedade da injustiça um fator comprobatório. O mundo enquanto vontade é violência, conflito e injustiça.

\section{CONCLUSÃO: ÉTICA E COMPAIXÃo}

É a partir das reflexões desenvolvidas anteriormente que Schopenhauer alcança o seu famoso pessimismo metafísico, sobremaneira expresso na máxima "viver é sofrer"34. A vida é a luta incessante e sem vitória derradeira, sucessão de desventuras e alegrias fugazes, de tal modo que, no fim, “a nossa condição é tão miserável que lhe seria preferível o não ser absoluto."35 A vida do indivíduo, a sua constituição mesma enquanto tal, é, como vimos, um agon incessante. Ele, o indivíduo, é um mero fenômeno, expressão da Vontade, e nesta não tem qualquer conforto ou piedade, mas apenas a imposição do desejar eterno e nunca satisfeito. Como coloca Schopenhauer, “cada biografia é uma história de dor." ${ }^{36}$ Diante de tal visão, a negação da Vontade ao modo

31 Sobre este ponto, escreve muito bem Ramos: “a injustiça é a invasão no domínio onde se afirma a vontade do outro: uma ação injusta é aquela que consiste na destruição ou ferimento do corpo do outro, ou então na redução das forças desse corpo ao seu próprio serviço; assim o injusto aumenta as forças ao seu serviço e ultrapassa essa soma de recursos que é seu próprio corpo, ele afirma a sua própria vontade para além dos seus próprios limites e o faz negando a vontade manifestada num corpo estranho." (Ramos, 2012, p. 175)

32 Schopenhauer, 2015, p. 393

33 Ramos, 2012, p. 175.

34 Schopenhauer, 1983, p. 73

35 Ibidem, p.90

36 Idem. 
do ideal ascético é a sua saída ética. Se a Vontade, enquanto manifestação fenomênica, é conflito a única possibilidade é voltá-la contra si mesmo na forma de um querer o não-querer. Tal negação, como bem coloca Barboza (2014), passa pela contemplação estética e pela compaixão; no primeiro caso, diante de uma obra de arte, a Vontade em sua agonística fenomênica entra em suspenso, permitindo a supressão da individualidade na pura contemplação. No segundo, o amor incondicional pelo próximo suprime o indivíduo que já não mais distingue o seu sofrimento dos outros: “em ambos os casos, tanto o contemplador do belo, quanto o agente compassivo têm uma 'visão através' do princípio de individuação."37 Somente na supressão do indivíduo através da negação da Vontade que o sofrimento pode ser superado na medida que o próprio indivíduo é suprimido em direção ao Outro. Se a Vontade na sua objetivação é conflito, ela em si permanece Una, e é nesta unidade ontológica primordial que a ação ética é possível. A fundamentação da ética, então, para Schopenhauer é indissociável de uma metafísica. Quanto a isso, escreve muito bem Leo Staudt:

É aqui que identificamos que o sentimento da compaixão, da unidade metafísica de todos os seres, o verdadeiro sentido moral da ação humana como negação da Vontade, só são possíveis mediante a unidade de ética e da metafísica. Assim como a Vontade é a essência de todos os seres, pela contemplação estética e pela compaixão, autêntica motivação moral e verdadeiro caminho para toda negação do querer, o indivíduo deixa de estar submetido ao princípio da razão suficiente e supera a separação do eu e do não eu. ${ }^{38}$

Se a Vontade é contradição na medida em que se manifesta através de um movimento imanente no mundo da representação, a partir deste é possível, ao sujeito, a contradição da própria contradição; contradizer a contradição agônica da vontade fenomênica em direção a esta mesma vontade enquanto unidade de todas as coisas, onde o eu é um Outro. A alteridade íntima do sujeito, a sua existência numênica enquanto pura Vontade, o faz enxergar no sofrimento do outro o seu próprio, para além do véu fenomênico, de tal modo que quem sofre não é mais o Outro, mas a si mesmo. Para isso, no entanto, a violência da Vontade em sua manifestação deve ser negada, seja pela mortificação corporal, pela ascese, seja pelo pensamento racional, de tal modo que a

37 Barboza, 2014, p. 188

38 Staudt, 2007, p. 301 
Vontade se aquiete, se enfraqueça, e assim permita ao sujeito contemplar a sua pertença ontológica a realidade em si mesma enquanto unidade indissolúvel da Vontade. Anteriormente, demonstramos como a injustiça, em Schopenhauer, se revela como primeira em relação à justiça. Isto não o impede, no entanto, de concluir por uma justiça eterna no seio mesmo do mundo enquanto Vontade. A compaixão, como fundamento de uma ética baseada na identificação metafísica do indivíduo ao mundo em si para além do princípio de individuação, permite acessar a dimensão própria da justiça eterna. O agon da Vontade só existe no mundo dos fenômenos, no seu movimento de objetivação. Mas se a Vontade, como vimos, é violência e contradição, no que consiste esta justiça eterna? Não se trata, com efeito, de uma justiça eterna ao modo cristão, uma justiça distributiva governada por um deus exterior ao mundo. A justiça eterna de Schopenhauer, diferentemente, consiste no fato de que cada mal realizado, cada dor provocada por um agente sob outro, no fundo é sentido pelo próprio agente uma vez que todos os indivíduos são o mesmo: “[...] a diferença entre quem inflige o sofrimento e quem tem de suportá-lo é apenas fenômeno e não atinge a coisa em si, isto é, a Vontade que vive em ambos"39. Deste modo, "torturador e o torturado são em si um.”40 Neste sentido, então, a compaixão permite olhar, para além do agon da Vontade em sua manifestação fenomênica - onde a injustiça é primária -, o mundo em si para além do princípio de individuação - onde a identidade metafísica de todos os seres garante uma justiça eterna na medida em que sofredor e algoz são um e o mesmo.

Como base no aqui exposto, esperamos ter demonstrado como na metafísica de Schopenhauer não temos uma natureza bifurcada, mas um contínuo que não separa homem e mundo. Se se mantém uma distinção entre coisa em si e fenômeno, esta distinção é sublevada na medida mesma em que este em si - a Vontade - não se subordina ao sujeito, mas antes, este àquele. Esperamos ter demonstrado como o antropomorfismo, então, se revela na busca schopenhaueriana do em si do mundo no em si da experiência. Neste movimento, o filósofo encontra violência, contradição e injustiça, no seio do movimento imanente de individuação fenomênica a partir da Vontade. No entanto, como demonstramos nesta conclusão, isto não impede uma ética. Se o mundo em sua manifestação é violência, a compaixão nos permitiria acessá-lo na sua

39 Schopenhauer, 2015, p. 411

40 Ibidem, p. 415 
unidade fundamental de forma a orientarmos nossa ação sob o princípio de que o eu, em sua intimidade metafísica, é Outro. Nesta unidade, em detrimento da injustiça primária, temos a justiça eterna na unidade da Vontade.

\section{BIBLIOGRAFIA}

BARBERA, Sandro. Une philosophie du conflit: Études sur Schopenhauer. PUF: Paris, 2004. BARBOZA, Jair. Negação da Vontade e significação moral do mundo em Schopenhauer. In: Metafísica e significação moral do mundo Vol.1. Ed. UECE: Fortaleza, 2014.

BARROS, Roberto. Metafísica imanente: Schopenhauer como ponto de inflexão. In: Revista Voluntas: Estudos sobre Schopenhauer-Vol. 8, No 2., 2017.

BITTENCOURT, Renato. Desejo, renúncia, ascese e salvação em Schopenhauer. In: Revista Voluntas: Estudos sobre Schopenhauer-Vol. 7, No 2., 2016.

CARTWRIGHT, David. Schopenhauer's Narrower Sense of Morality. In: The Cambridge Companion to Schopenhauer. Ed. Cristopher Janaway. Cambridge Company Press: Londres, 2006.

DANOWSKI, Déborah. CASTRO, Eduardo. Viveiros de. Há mundo por vir? Ensaio sobre os medos e os fins. Florianópolis: Desterro: Cultura e Barbárie: Instituto sócioambiental, 2014

DELEUZE, Gilles. Diferença e Repetição. Trad. Luiz Orlandi e Roberto Machado Lisboa: Relógio D’água, 2000.

MONTEBELLO, Pierre. Métaphysiques Cosmomorphes: La fin du monde humain. Les presses du réel: Dijon, 2015.

NOGUEIRA, Renato. A ética da compaixão na filosofia de Schopenhauer. Disponível em: http://www.ufrrj.br/graduacao/prodocencia/publicacoes/eticaalteridade/artigos/Renato_Nogueira.pdf. Último acesso a: 10/10/2017.

RAMOS, Flamarion. A teoria da justiça de Schopenhauer. In: Revista Ethic@, V.11, $\mathrm{N}^{\circ} 2$, 2012. 
RUGGIERI, Davide. The metaphysics of conflict: some reflections on Schopenhauer's politics. In: Revista Voluntas: Estudos sobre Schopenhauer, Vol. 7, No 1. 2016.

SCHOPENHAUER, Arthur. O Mundo como Vontade e Representação Tomo I. Trad. de Jair Barboza. Editora Unesp: São Paulo, 2015.

- O Mundo como Vontade e Representação. Trad. de Heraldo Barbuy, Editora de Ouro; Rio de Janeiro, 1986.

Sobre a Vontade na Natureza. Trad. de Gabriel Valladão Silva. L\&PM:

Porto Alegre, 2013 .

SKRBINA, David. Panpsychism in the West. MIT Press: Londres, 2005.

STAUD, Leo. O significado moral das ações como negação da Vontade para Arthur Schopenhauer. Rev. Filos., v. 19, n. 25, 2007

SHAVIRO, Steven. Whithout Criteria: Kant, Whitehead, Deleuze and Aesthetics. Londres: MIT Press, 2009.

WHITEHEAD, Alfred. O Conceito de Natureza. Trad. Julio Fischer. São Paulo: Martins Fontes, 1994. 